

Available online at www.entomoljournal.com

E-ISSN: 2320-7078

P-ISSN: 2349-6800

JEZS 2017; 5(1): 732-733

(C) 2017 JEZS

Received: 10-11-2016

Accepted: 11-12-2016

Mark Ian Cooper

Department of Biological

Sciences, University of Cape

Town, Rondebosch, Republic of

South Africa
Correspondence

Mark Ian Cooper

Department of Biological

Sciences, University of Cape

Town, Rondebosch, Republic of

South Africa

\section{The affect of female body width on copulation duration in Centrobolus inscriptus (Attems)}

\section{Mark Ian Cooper}

\section{Abstract}

Body size is a known correlate of copulation duration in Centrobolus inscriptus. I tested for the presence of a relationship between female body width and copulation duration in C. inscriptus by performing mating experiments. Females differed significantly from males in body mass, body length, and dorsal tergite width. Female width was positively related to copulation duration. Larger females are expected to be more fecund.

Keywords: Arthropods, body size, Centrobolus, copulation duration

\section{Introduction}

Male and female body sizes can influence the duration of copulation in arthropods ${ }^{[1]}$. Body size and morph are known drivers of copulation duration ${ }^{[2]}$. These factors may be interdependent ${ }^{[3]}$. The interdepence of male and female body size on each other is manifest in the relationship between reversed sexual size dimorphism (SSD) and copulation duration ${ }^{[4]}$. Here I test for the presence of a relationship between female body width and copulation duration in the millipede Centrobolus inscriptus. The null hypothesis is there is no relationship between female body width and copulation duration in any of the matings.

\section{Materials and methods}

Millipedes were collected in April 1995 from Zululand (Twin streams farm, Mtunzini). Live specimens of each sex were transported to the laboratory where conditions were kept under a constant regime of $25{ }^{\circ} \mathrm{C}$ temperature; $70 \%$ relative humidity; 12: 12 hrs light-dark cycle. Food was provided in the form of fresh vegetables ad libitum. Individuals had unknown mating histories. Unisex groups were housed in plastic containers containing moist vermiculite ( $\pm 5 \mathrm{~cm}$ deep) for 10 days before commencing the first mating experiments. Three measurements were taken for all individuals once copula pairs had disengaged; body mass (accurate to $0.01 \mathrm{~g}$ ), body length $(\mathrm{mm})$, and dorsal tergite width $(\mathrm{mm})$. Dorsal tergite width was measured horizontally using Vernier callipers. Animals were placed into glass mating arenas (30 X 22 X $22 \mathrm{~mm})$. Individuals were marked on the posterior segments with coloured tipex fluid (perfect A16) prior to mating. This allowed data from each individual to be integrated. Single, double, and artificially-terminated mating with females were allowed. Approximately five minutes after establishing copula pairs were removed from the mating arena and placed into plastic beakers $(13 \mathrm{~cm}$ diameter). This prevented interference from other males and allowed easy timing of the copulation durations. Statistical analyses were performed using Statgraphics (version 6.0). Morphometric data were tested for normality before comparing males and females using a Student's t-test.

\section{Results}

Larger females tended to copulate for longer than their smaller conspecifics in C. inscriptus (r $=0.63, \mathrm{n}=30, p<0.05$ ). Although female girth was positively related to copulation duration, the absence of this relationship in the first copulation durations of double mating $\left(\mathrm{r}_{\mathrm{s}}=0.19, \mathrm{n}=\right.$ $46, \mathrm{P}=0.22$ ) means that a type II error was possible. Female girth was again positively correlated to the second copulation duration $\left(\mathrm{r}_{\mathrm{s}}=0.31, \mathrm{n}=46, \mathrm{P}=0.04\right)$, suggesting that this is no artefact and should be discussed further. 


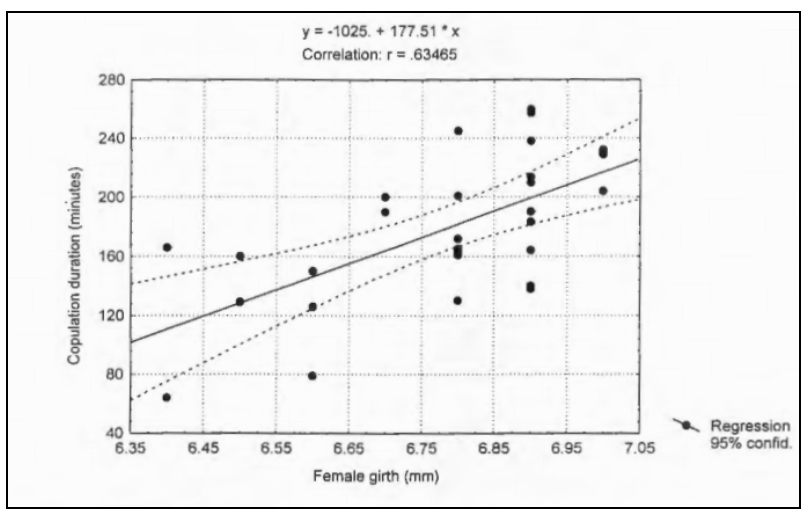

Fig 1: Regression of copulation duration on female body width in the millipede Centrobolus inscriptus.

\section{Discussion}

The null hypothesis was falsified and a relationship between female width and copulation duration was found. Females appear able to control copulations in accordance with their body size, which may relate to fecundity. Two reasons can be given for why larger females endure longer copulations: larger females endure to control the duration of copulation and benefit from improved fecundity and fertility. This may come about through maximizing her intake of ejaculate or some other nutrient-rich substance produced by the male; predicting a correlation between ejaculate volume or material benefits with copulation duration. Larger females are also expected to carry a larger number of ova ${ }^{[1]}$.

\section{Conclusion}

Copulations of females were significantly related to female body width in the presence of sexual size dimorphism in double mating experiments of $C$. inscriptus.

\section{References}

1. Lefranc A, Bungaard J. The influence of male and female body size on copulation duration and fecundity in Drosophila melanogaster. Hereditas. 2000; 132:243-247. DOI: $10.1111 /$ j.1601-5223.2000.00243.x.

2. Wong-Muñoz J, Anderson $\mathrm{CN}$, Munguía-Steyer $\mathrm{R}$, Córdoba-Aguilar A. Body Size and Morph as Drivers of Copulation Duration in a Male Dimorphic Damselfly. Ethology. 2013; 119(5):407-416. DOI: $10.1111 /$ eth.12077.

3. Walzer A, Schausberger P. Interdependent effects of male and female body size plasticity on mating behaviour of predatory mites. Animal Behaviour. 2015; 100:96-105. http://dx.doi.org/10.1016/j.anbehav.2014.11.017.

4. Cooper MI. Sexual conflict over duration of copulation in Centrobolus inscriptus (Attems). Journal of Entomology and Zoology Studies. 2016; 4(6):852-854. DOI: 10.13140/RG.2.2.31736.24325.

5. Lawrence RF. The centipedes and millipedes of southern Africa: A guide. Cape Town \& Rotterdam: A.A. Balkema, 1983.1 ISBN 10: 0869611429 ISBN 13: 9780869611425. 